\title{
Embryonic Development and Comparative Anatomy of the Mandible
}

\author{
Shaibu Mohammed Atabo ${ }^{1,2^{*}}$, Abubakar Abubakar Umar ${ }^{2}$, Sani Abdullahi Shehu ${ }^{2}$, \\ Adamu Abdul Abubakar ${ }^{3}$ \\ ${ }^{1}$ Department of Veterinary Anatomy, Bayero University, Kano, Nigeria. \\ ${ }^{2}$ Department of Veterinary Anatomy, Usmanu Danfodiyo University, Sokoto, Nigeria. \\ ${ }^{3}$ Department of Veterinary Surgery and Radiology, Usmanu Danfodiyo University, Sokoto, Nigeria.
}

Received 18 September 2020; Revised 16 January 2021; Accepted 03 February 2021; Published 01 March 2021

\begin{abstract}
Objective: This study was designed to determine the ossification time and pattern of the mandible. Methodology: Three hundred and fifty (350) wasted fetuses consisting of 70 Balami, 140 each of Uda and Yankasa breeds whose crown vertebral rump length ranged from 3.0-15 cm were used. The fetuses were processed using the Alizarin technique and the mandible was dissected from the head for stereography. Result: The result revealed that the first part of the mandible to develop was the body and mental foramina at the $42^{\text {nd }}-44^{\text {th }}$ days of gestation while the coronoid process, rami, and condyloid process develop later at different time points. In addition, the mandibular foramina remained undeveloped in all age groups. Interestingly, the mandibular canal began ossification earlier in the Yankasa breed compared to other breeds. It was shown to arise from a cartilaginous tissue at the medial and lateral surfaces of the body and dorsally remained opened and undifferentiated from the teeth alveoli of the lower jaws in the 7 age groups. Conclusion: It was therefore concluded that the mandible arises from three ossification centres at the body, rami, and coronoid process. These segments develop at different time intervals in the three breeds of sheep with Yankasa mandible ossifying and progressing faster than in Balami and Uda.
\end{abstract}

Keywords: Ossification Centre; Mandible; Foramen; Balami; Uda; Yankasa.

\section{Introduction}

The mandible is the largest and strongest bone of the skull. It forms the lower jaw and accommodates the lower incisors, premolar, and molar teeth in ruminants [1]. The mandible articulates with the temporal bone to form the only movable joint of the skull referred to as the temporo-mandibular joint which plays a major role in apprehension and chewing [2,3]. Studies on the development of the skull, especially the mandible in animals are still scanty [4]. Ahmed and Mahmood (2011) [5] and Ahmed (2003) [6] have previously examined the development of the mandible in Iraqi breed of sheep and Iraqi Black goats respectively. The development of the mandible begins with the formation of a cartilage (Meckel's cartilage) [7] and continues by laying down new bone material in the fibrous membrane covering the outer surfaces of the cartilage $[8,9]$. Details on the developmental anatomy of the mandible are vital in diagnosing and understanding the pathogenesis of oral disorders such as malocclusion, prognathism, and brachignatia [10]. According to Arcaute at al. (2020) [11] hard foods with sharp edges such as maize straw as well as acidic foods such as silages favor the development of mandibular disorders in Spanish sheep. Oral disorders of sheep can cause

\footnotetext{
* Corresponding author: mohakosh@yahoo.com

do) http://dx.doi.org/10.28991/SciMedJ-2021-0301-3

$>$ This is an open access article under the CC-BY license (https://creativecommons.org/licenses/by/4.0/).

(C) Authors retain all copyrights.
} 
significant economic losses in farms, prevent animals from feeding properly, leading to weight loss and culling of the animals [12]. Camacho-Alonso et al. [13] compared new bone formation in critical mandibular defect in healthy, diabetic, and osteoporotic rats administered with hydroxyapatite (HA) alone and HA combined with simvastatin (SV) and reported that combined application of HA and SV improves mandibular bone regeneration compared with HA alone in healthy, diabetic, and osteoporotic rats. The present study was designed to investigate the normal pattern of development/ossification of the mandible in three Nigerian breeds of sheep. The study of normal embryonic and fetal growth of the mandible can serve as a guide for age estimation, contribute to the knowledge of developmental anatomy and helps to understand the consequences of harmful influences at various stages of gestation [14].

\section{Materials and Methods}

\subsection{Sample Collection}

The present study utilized a total of three hundred and fifty (350) fetal samples of three Nigerian breeds of sheep whose Crown Vertebral Rump Length (CVRL) ranged from 3.0-15 cm (modified from irrespective of sex [15]. The fetuses studiedcomprised of seventy (70) Balami, one hundred and forty (140) Uda, and one hundred and forty (140) Yankasa breeds. Fetal samples were collected over a one year period from their geographically dominated areas; north-east in Gombe state township abattoir (for Balami samples), and north-west in Kaduna and Zamfara state (for Yankasa samples), and in Sokoto state (for Uda samples) abattoirs of Nigeria.

\subsection{Aging and Sample Preparation}

The crown vertebral rump length (CVRL) of the fetal samples were obtained with a measuring tape, extending from the anterior fontanel and following the vertebral column down to the base of the tail to determine the gestational ages in days using the formula: $\mathrm{X}=2.1(\mathrm{Y}+17)$ where $\mathrm{X}=$ Gestational Age in days and $\mathrm{Y}=$ Crown Vertebral Rump Length [16], based on their age, they were classified into seven age groups ranging from $42^{\text {nd }}-67^{\text {th }}$ days of gestation. The fetuses were immediately transported in an ice packs to the Veterinary Anatomy Laboratory of Usmanu Danfodiyo University Sokoto for further analysis.

\subsection{Staining Technique}

The fetuses were subjected to the Alizarin staining technique, according to the procedure described by Salaramoli et al. (2015) [17] with little modification. Briefly, the fetuses were skinned, eviscerated, and fixed in 95\% ethanol (LobalChemie $^{\circledR}$, Mumbai India) for 6 and 8 hours for smaller and larger sized fetuses respectively. The fixed fetuses were stained in a mixed alcoholic solution and $0.3 \%$ Alizarin red (LobalChemie ${ }^{\circledR}$, Mumbai India) for 17 hours. The bones were macerated using 2-10\% potassium hydroxide $(\mathrm{KOH})$ (LobalChemie $囚$, Mumbai India) for 6-24 hours and $8-10 \% \mathrm{KOH}$ for 20-24 hours for smaller and larger sized fetuses respectively. The macerated samples were cleared using gradual concentrations of glycerin (LobalChemie ${ }^{\circledR}$, Mumbai India) in distilled water $(20,50$ and $80 \%$ ) for 14 hours. It was then placed in a glycerin-distilled water mixture and mounted on a dissecting microscope (Leica ${ }^{\circledR}$ ), the mandible was micro-dissected from the skull, examined and its stereographs were captured using a 7.2 Megapixel Panasonic Lumixdigital camera. The flowchart of the research methodology is as shown in Figure 1.

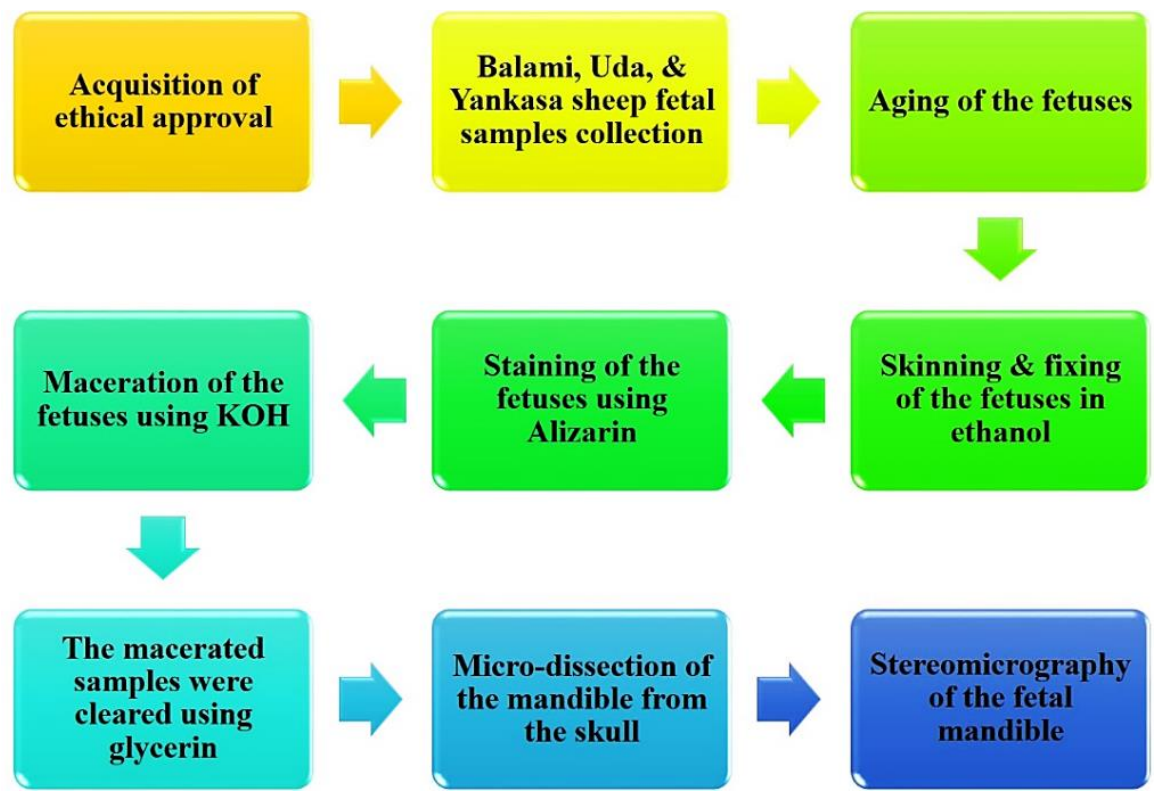

Figure 1. A flowchart showing the research methodology 


\section{Results}

\subsection{Ossification of the Mandible}

The different parts of the mandible in the three breeds of sheep developed at different time intervals from different ossification centres. The ossification of the mandible began with the establishment of a Meckel's cartilage. Bony tissues were formed on the cartilage, beginning from the lateral surface and extending to the medial surface of the meckel's cartilage. The appearance of the bony tissues on the cartilage is marked by the red coloration and hardening of the mandible. The red coloration was due to the reaction of the newly laid bony tissue and the Alizarin Red stain. The cartilage was gradually replaced by the bony tissue formed through ossification. The mandible was largely cartilaginous and bony tissues in the $42^{\text {nd }}-44^{\text {th }}$ and $61^{\text {st }}-67^{\text {th }}$ days of gestation respectively (Figures $2 \mathrm{a}$ and $5 \mathrm{a}$ ). The first and last parts to ossify were the body (horizontal part) and the condyloid process of the rami (vertical part) respectively (Figures $2 \mathrm{a}$ and $5 \mathrm{a}$ ).

This study showed that the ossification of the mandibular body (MB) of the Yankasa, Uda, and Balami occurred at the $42^{\text {nd }}-44^{\text {th }}$ days of gestation of the first trimester fetuses, however the ossification was incomplete and some cartilages were seen around the MB (Table 1 and Figure $2 \mathrm{a}$ ) At the $61^{\text {st }}-67^{\text {th }}$ days of gestation, the ossification of the MB was complete and all the cartilages were replaced with bony structures (Figure 5a). The ossification of the mandibular body began from the ossification centre cranial to the mental foramen and extended caudally across the horizontal axis of the mandible. The alveoli region of the incisors teeth (cranial end of the mandible) were cartilaginous at $42^{\text {nd }}-45^{\text {th }}$ days (Figure $2 \mathrm{a}$ ) and began to ossify at $61^{\text {st }}-66^{\text {th }}$ days of gestation (Figures 2 a to $5 \mathrm{a}$ ) across the three breeds. An arc-shaped coronoid process $(\mathrm{CrP})$ of the mandible appeared and began to ossify independently from the ossification centre on its proximal end, along with the cartilaginous tissues of the mandibular rami (vertical body) at $45^{\text {th }}-47^{\text {th }}$ days of gestation in Yankasa ( $1^{\text {st }}$ trimester $)$ and $51^{\text {st }}-53^{\text {rd }}$ days of gestation $\left(2^{\text {nd }}\right.$ trimester $)$ in Uda and Balami. The coronoid process was seen as a cartilaginous process at $42^{\text {nd }}-44^{\text {th }}$ days of gestation and its ossification emerged from a new and separate ossification centre and ossified gradually in a caudo-ventral direction to meet the mandibular rami (Figures $2 \mathrm{a}$ to $4 \mathrm{a}$ ). The mandibular rami (MR) began to ossify at $57^{\text {th }}-60^{\text {th }}$ days of gestation in Yankasa and $61^{\text {st }}-67^{\text {th }}$ days of gestation in Uda and Balami (Table 1) from the ossification centre at its dorsal part. The mandibular rami (vertical parts of the mandible) were also seen to gradually ossify dorso-ventrally from cartilaginous tissue extending from the body at an angle of $105^{\circ}$ at $45^{\text {th }}-47^{\text {th }}$ days and later $95^{0}$ at $61^{\text {st }}-67^{\text {th }}$ days.

The teeth of the lower jaws were yet to develop within the 7 age groups (Figures 2a to 5a). The condyloid processes $(\mathrm{CoP})$ in the three breeds were absent from the $1^{\text {st }}$ to the $5^{\text {th }}$ age groups $\left(42^{\text {nd }}-56^{\text {th }}\right.$ days of gestation). It then began to ossify at $57^{\text {th }}-60^{\text {th }}$ days of gestation in Yankasa and $61^{\text {st }}-67^{\text {th }}$ days of gestation in Uda and Balami breeds. A mandibular notch developed between the condyloid process and coronoid process as the ossification of the two processes progressed dorsally from the body of the mandibular rami along the coronoid process (Table 1 and Figure $4 \mathrm{Ba})$.

Table 1. Time and sequence of ossification of the Mandible in the three breeds of sheep

\begin{tabular}{|c|c|c|c|c|c|}
\hline \multirow{2}{*}{$\begin{array}{l}\text { Age groups } \\
\text { (days) }\end{array}$} & \multirow[b]{2}{*}{ Breeds } & \multicolumn{4}{|c|}{ Parts of the mandible } \\
\hline & & MB & $\mathrm{CrP}$ & MR & CoP \\
\hline \multirow{3}{*}{$\begin{array}{c}\text { One } \\
(42-44) \\
1^{\text {st }} \text { Trimester }\end{array}$} & Yankasa & Ossified & - & - & - \\
\hline & Uda & Ossified & - & - & - \\
\hline & Balami & Ossified & - & - & - \\
\hline \multirow{3}{*}{$\begin{array}{c}\text { Two } \\
(45-47) \\
1^{\text {st }} \text { Trimester }\end{array}$} & Yankasa & Ossified & Ossified & - & - \\
\hline & Uda & Ossified & - & - & - \\
\hline & Balami & Ossified & - & - & - \\
\hline \multirow{3}{*}{$\begin{array}{c}\text { Three } \\
(48-50) \\
1^{\text {st }} \text { Trimester }\end{array}$} & Yankasa & Ossified & Ossified & - & - \\
\hline & Uda & Ossified & - & - & - \\
\hline & Balami & Ossified & - & - & - \\
\hline \multirow{3}{*}{$\begin{array}{c}\text { Four } \\
(51-53) \\
2^{\text {nd }} \text { Trimester }\end{array}$} & Yankasa & Ossified & Ossified & - & - \\
\hline & Uda & Ossified & Ossified & - & - \\
\hline & Balami & Ossified & Ossified & - & - \\
\hline \multirow{3}{*}{$\begin{array}{c}\text { Five } \\
(54-56) \\
2^{\text {nd }} \text { Trimester }\end{array}$} & Yankasa & Ossified & Ossified & - & - \\
\hline & Uda & Ossified & Ossified & - & - \\
\hline & Balami & Ossified & Ossified & - & - \\
\hline \multirow{3}{*}{$\begin{array}{c}\text { Six } \\
(57-60) \\
2^{\text {nd }} \text { Trimester }\end{array}$} & Yankasa & Ossified & Ossified & Ossified & Ossified \\
\hline & Uda & Ossified & Ossified & - & - \\
\hline & Balami & Ossified & Ossified & - & - \\
\hline \multirow{3}{*}{$\begin{array}{c}\text { Seven } \\
(61-67) \\
2^{\text {nd }} \text { Trimester }\end{array}$} & Yankasa & Ossified & Ossified & Ossified & Ossified \\
\hline & Uda & Ossified & Ossified & Ossified & Ossified \\
\hline & Balami & Ossified & Ossified & Ossified & Ossified \\
\hline
\end{tabular}

Key: Mandibular body (MB), Coronoid process (CrP), Mandibular rami (MR), Condyloid process (CoP) 

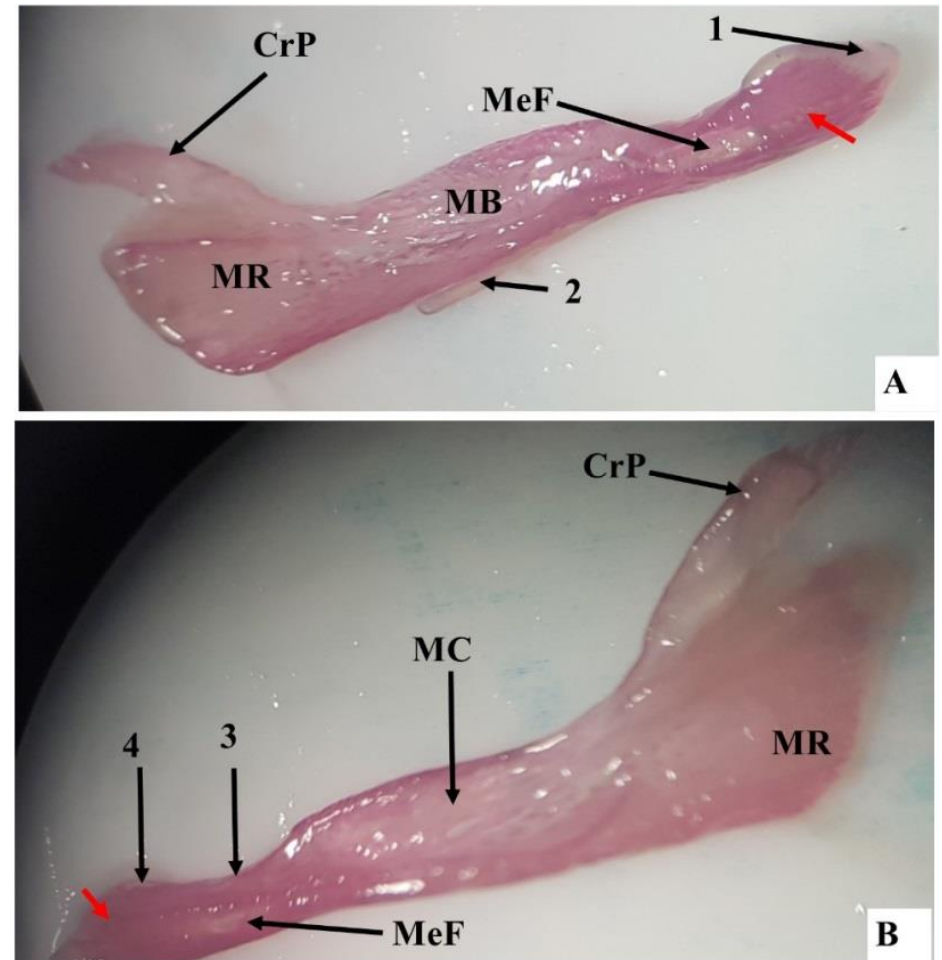

Figure 2. A stereomicrograph of the lateral (A) and dorsomedial view (B) of a $42^{\text {nd }}$ day-old Yankasa mandible, ossification centres (red arrow) showing mental foramen (MeF) and Meckel's cartilage on the body (2) and cartilaginous alveoli, mandibular body, mandibular rami, and coronoid process (1, MB, MR, CrP respectively), the mandibular incisure (3), lingual surface (4), and the mandibular canal (MC), Alizarin red stain (X5).

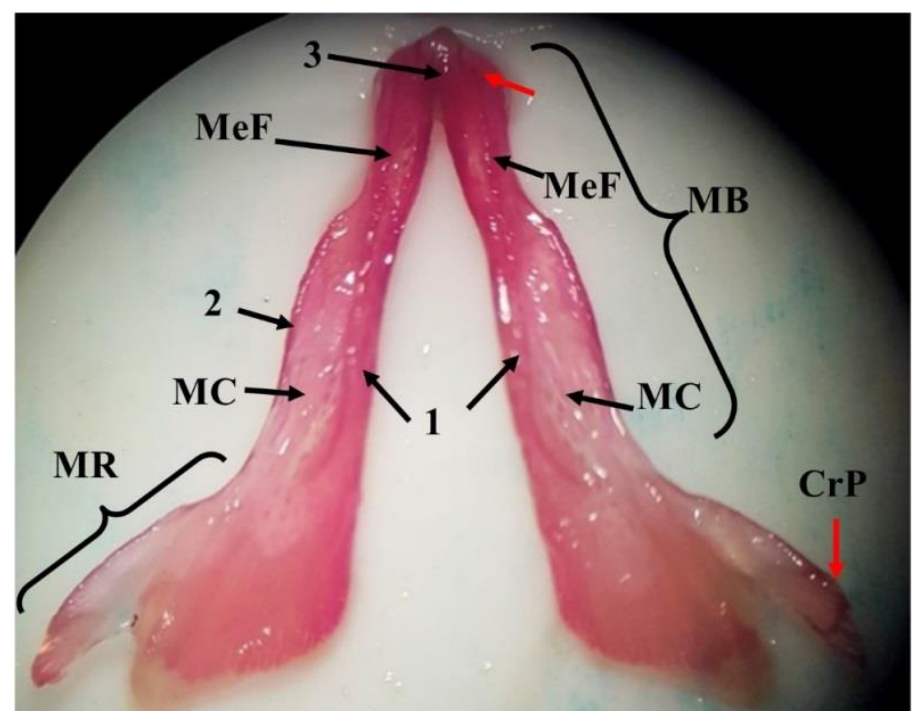

Figure 3. A stereomicrograph of a dorsomedial view of the mandible in a $45^{\text {th }}$-day old Yankasa fetus, showing mandibular body (MB), mandibular rami (MR), mental foramen (MeF), mandibular canal (MC), ossification centres (red arrows), and ossifying medial (1) and lateral (2) parts of MB, mandibular symphysis (3), and coronoid process (CrP), Alizarin stain (X5).

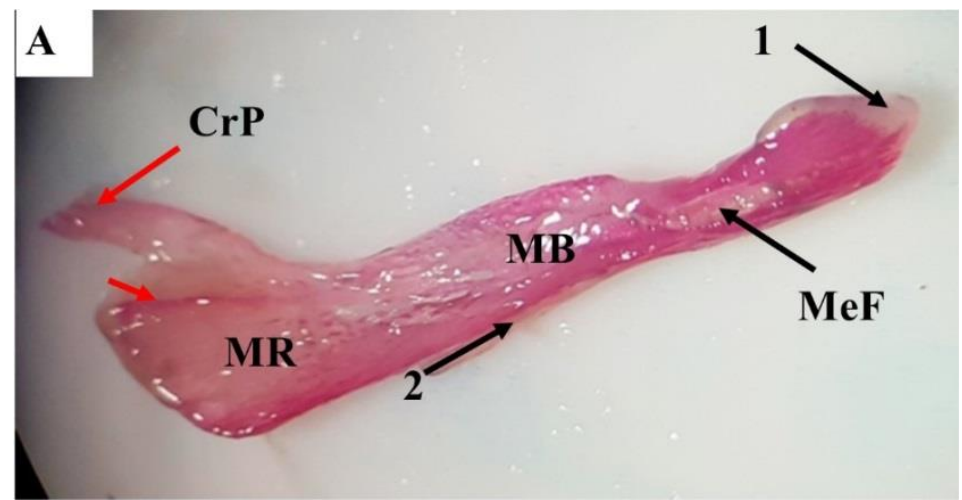




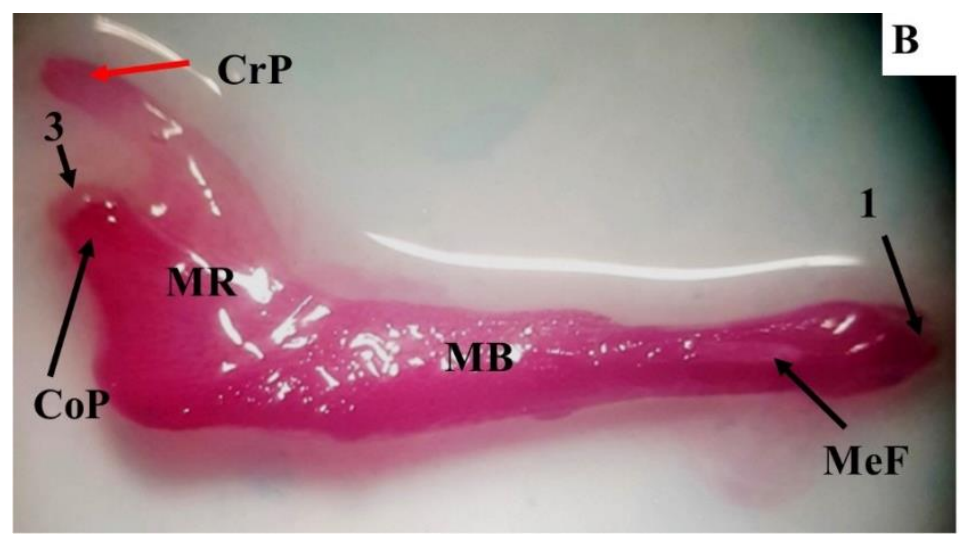

Figure 4. A stereomicrograph of the lateral views of the mandible of a $51^{\text {st }}(\mathrm{A})$ and $66^{\text {th }}(\mathrm{B})$ days old Uda fetus showing the ossifying mandibular body (MB), mandibular rami (MR), ossification centres (red arrows), ventral border (2) coronoid process $(\mathrm{CrP})$, condyloid process (CoP) and its fibrous extremity (3), cartilaginous alveolus for incisors teeth (1) and ossified alveolus for incisors teeth (4), and mental foramen (MeF), Alizarin red stain (X5).
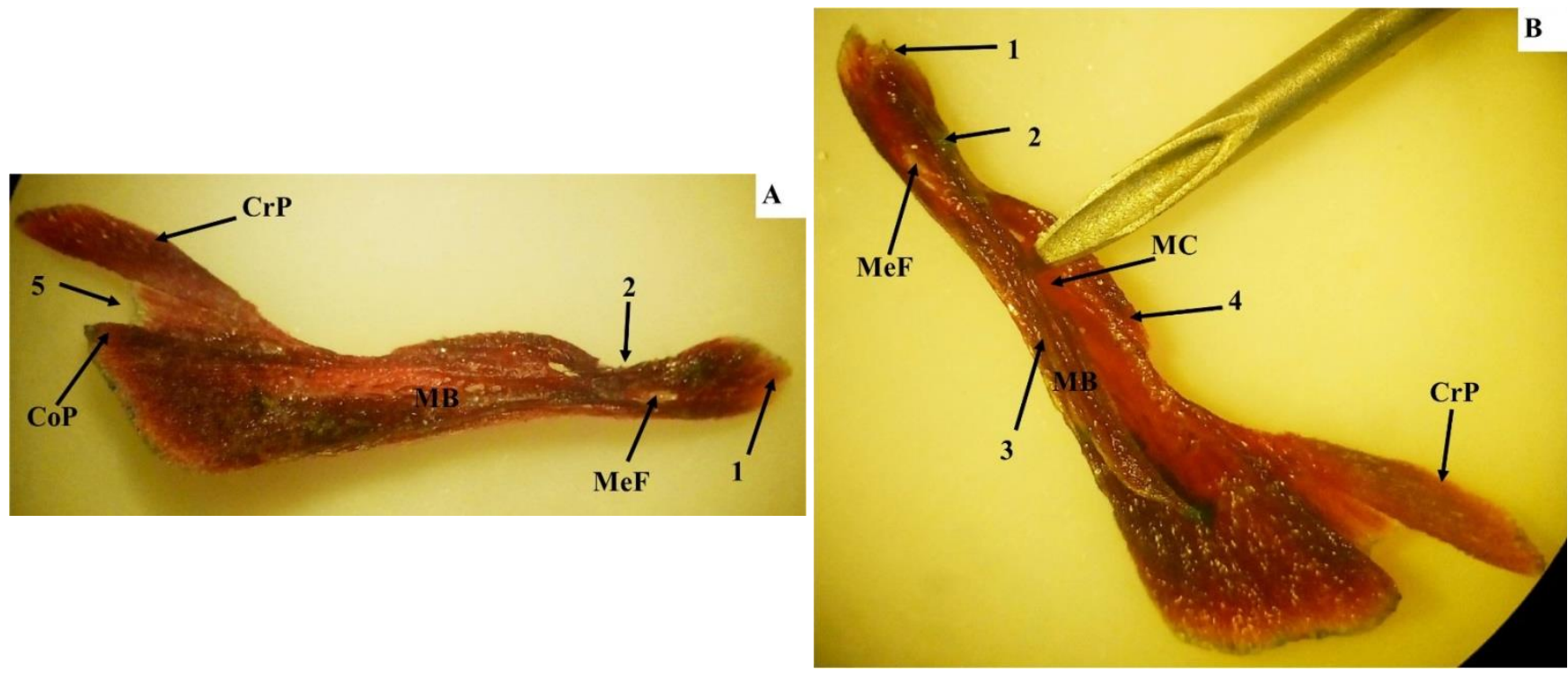

Figure 5. A stereomicrograph of the lateral (A) and dorsomedial view (B) of a $67^{\text {th }}$ day old Balami fetal mandible, showing the mandibular body (MB) mandibular rami (MR) mental foramina (MeF) and opened mandibular canal (MC), coronoid processes (CrP), alveolus for incisors teeth (1), mandibular incisure (2), medial part of MB (3) and lateral part of MB (4), and intercondylar notch (5), Alizarin stain (X5).

\subsection{Development of the Mandibular and Mental Foramina}

During ossification, the mental foramen (MeF) appeared as a cone-shaped opening from 42nd - 44th days of gestation in the three breeds of sheep on the cranio-lateral surface of the developing mandibular body (MB) (Figure 2a). The developing mental foramen was also visible on the medial surface and it has no linkage with any canal. In the 7 age groups, the mandibular foramen $(\mathrm{MaF})$ was undeveloped. During the formation of the mandibular body, it has left and right cartilaginous parts and the dorsal edges of these parts gradually curved dorso-medially towards each other to form an incomplete mandibular canal (MC). The developing MC was opened dorsally and closed ventrally throughout its length from the cranial to the caudal end and it was undifferentiated from the openings of the alveoli teeth of the lower jaws and they both exist as a single entity with no clear demarcation (Table 2 and Figure 4). All the teeth of the lower jaw were absent across all the age groups.

\section{Discussions}

The mandible was observed to be the first part of the skull to begin ossification, and its ossification occurred on both sides of the jaw via intramembranous ossification. This agrees with the result of Ahmed (2003) [6] who mentioned that in the Iraqi native black goat, early mineralization of skull bones was concentrated bilaterally in equal size around the oral region within the mandible and that each half of the mandible develops as a single skeletal element. Although the time of appearance of primary ossification centres of the mandible reported by Ahmed [6] in the Iraqi native black goat ( $39^{\text {th }}$ day of gestation) was a little earlier than in the Nigerian breeds of sheep. Rice (2008) [18] also observed that the earliest distinct centre of ossification to appear in man is in the mandible although at a little 
older age ( $49^{\text {th }}$ day of gestation). Similarly, Ahmed and Mahmood (2011) [5] studied a $49^{\text {th }}$-day old fetal mandible of an indigenous Iraq sheep and reported that ossification of the mandible had set in. The difference in the time of appearance of the mandibular ossification centre was associated with species differences. Several authors have described the mandible as the largest bone of the skull with several parts. In this study, it was noted that the different parts of the cartilaginous mandible undergo intramembraneous ossification at a different time intervals due to the large size of the mandible. The ossification of the cartilaginous mandible begins from the rostral to the caudal parts. Although the most caudal and dorsal parts of the mandible, the coronoid process, began ossification earlier than mandibular rami and condyloid process, the separate ossification centres observed at the proximal coronoid process and proximal mandibular rami suggest that the ossification of the coronoid process could have emerged from a $2^{\text {nd }}$ ossification centre and the condyloid process and mandibular rami from a $3^{\text {rd }}$ ossification centre. This can be linked to the works of Hill (2020) [19] and Dunlop and Hall (2002) [20] who reported multiple ossification centres in the mandible. The mandibular notch formed during the ossification of the coronoid and condyloid process serves as the articular surface of the only movable joint of the skull (temporo-mandibular joint) [2].The endochondral ossification of the mandible began from the rostro-lateral part of the cartilaginous mandible around the mental foramen. These findings were in line with the work of several authors such as Hill (2020) [19]; Ahmad and Mahmood (2011) [5]; Amano et al. [21] who reported that the ossification centre of the mandible was situated in front of the developing mental foramen at the lateral sides of mesenchyme of first branchial arch (Meckel's cartilage) and that the rostral part of the mandible was developed by endochondral ossification. However, Frommer and Margolies [22] reported contrary findings in mice, stating that three ossification processes (two intramembranous and one endochondral) occurred concurrently in the anterior part of the mandible and that the contribution of the Meckel's cartilage was transient. This contradiction could be attributed to the differences in the gestation period and species variation.

The present study has also shown that the mental foramen develops earlier than the mandibular foramen in the three breeds of sheep and that the development occurs earlier in Yankasa than in Balami and Uda breeds. Although the earlier development of mental foramen compared to the mandibular foramen could be attributed to the the ossification of the mandible which began at the mandibular body, the varaitions observed among yenkasa, Balami and Uda could be due to breed difference. This particular finding agrees with the work of Ichim et al. [23] who reported that the initial site for mandibular osteogenesis is between the mental branches of the alveolar nerve at the rostral part of the Meckel's cartilage in human. The undifferentiated openings that formed the mandibular canal and teeth alveoli indicate that they both had a single origin during ossification. The absence of the mandibular foramen and incomplete mandibular canal in all the age groups implies that the mandibular foramen and canal takes longer time to develop in the Nigerian breeds of sheep, probably in the $3^{\text {rd }}$ trimester.

\section{Conclusion}

The mandible arises from three ossification centres and its different segments develop at different time intervals in the three breeds of sheep, with Yankasa mandible ossifying faster than in Balami and Uda breeds. The mandible begins as a cartilage but later ossifies into a bony tissue. Hence its ossification is said to be endochondrial.

\section{Declarations}

\subsection{Author Contributions}

This work was carried out in collaboration between all authors. S.M.A., A.A.U., S.A.S., and A.A.A. designed the study; S.M.A. performed the stereography, wrote the first draft of the manuscript and managed the literature review. All authors have read and agreed to the published version of the manuscript.

\subsection{Funding}

The author(s) received no financial support for the research, authorship, and/or publication of this article.

\subsection{Ethical Approval}

The study was approved by Institutional Animal Care and Use Committee of Usman Danfodiyo University Sokoto reference no. UDUS/FAREC/2019/AUP-RO-5.

\subsection{Data Availability Statement}

The data presented in this study are available on request from the corresponding author.

\subsection{Conflict of Interest}

The authors declare that they have no known competing financial interests or personal relationships that could have appeared to influence the work reported in this paper. 


\section{References}

[1] Dyce, K. M., Sack, W. O., \& Wensing, C. J. G. (2002). Textbook of Veterinary Anatomy, 3ed. WB Saunders, Philadelphia, p150.

[2] Dyce, K. M., Sack W. O., \& Wensing, C. J. G. (2017). Text book of Veterinary Anatomy. 5th edition, Saunders Elsevier Inc. Riverport Lane St. Louis, Missouri, 1117.

[3] Dyce, K. M., Sack, W. O. \& Wensing, C. J. G. (2010). Text book of Veterinary Anatomy 4th edition Saunders Elsevier Inc. 3251 Riverport Lane St. Louis, Missouri 63043 Pp644, 728-742

[4] Lipski, M., Tomaszewska, I. M., Lipska, W., Lis, G. J., \& Tomaszewski, K. A. (2013). The mandible and its foramen: anatomy, anthropology, embryology and resulting clinical implications. Folia Morphologica, 72(4), 285-292. doi:10.5603/fm.2013.0048.

[5] Ahmed, N. S. \& Mahmood, K. H. (2011). Development of mandible in indigenous sheep fetuses of Iraq. Iraqi Journal of Veterinary Sciences, 25(2), 99-106

[6] Ahmed, N. S. (2003). Development of the mandible in the native black goat fetuses. Iraqi Journal of Veterinary Sciences 7(1), $47-53$

[7] Anthwal, N., Urban, D. J., Luo, Z.-X., Sears, K. E., \& Tucker, A. S. (2017). Meckel's cartilage breakdown offers clues to mammalian middle ear evolution. Nature Ecology \& Evolution, 1(4). doi:10.1038/s41559-017-0093.

[8] Lautenschlager, S., Gill, P. G., Luo, Z.-X., Fagan, M. J., \& Rayfield, E. J. (2018). The role of miniaturization in the evolution of the mammalian jaw and middle ear. Nature, 561(7724), 533-537. doi:10.1038/s41586-018-0521-4.

[9] Ku, J.-K., Kim, Y.-K., \& Yun, P.-Y. (2020). Influence of biodegradable polymer membrane on new bone formation and biodegradation of biphasic bone substitutes: an animal mandibular defect model study. Maxillofacial Plastic and Reconstructive Surgery, 42(1). doi:10.1186/s40902-020-00280-5.

[10] Rasooli, A., Nouri, M., Esmaeilzadeh, S., Ghadiri, A., Gharibi, D., Koupaei, M. J., \& Moazeni, M. (2018). Occurrence of purulent mandibular and maxillary osteomyelitis associated with Pseudomonas aeruginosa in a sheep flock in south-west of Iran. Iranian journal of veterinary research, 19(2), 133-136.

[11] Ruiz de Arcaute, M., Lacasta, D., González, J. M., Ferrer, L. M., Ortega, M., Ruiz, H., ... Ramos, J. J. (2020). Management of Risk Factors Associated with Chronic Oral Lesions in Sheep. Animals, 10(9), 1529. doi:10.3390/ani10091529.

[12] Borsanelli, A. C., Gaetti-Jardim, E., Schweitzer, C. M., Viora, L., Busin, V., Riggio, M. P., \& Dutra, I. S. (2017). Blackpigmented anaerobic bacteria associated with ovine periodontitis. Veterinary Microbiology, 203, 271-274. doi:10.1016/j.vetmic.2017.03.032.

[13] Camacho-Alonso, F., Martínez-Ortiz, C., Plazas-Buendía, L., Mercado-Díaz, A. M., Vilaplana-Vivo, C., Navarro, J. A., ... Martínez-Beneyto, Y. (2020). Bone union formation in the rat mandibular symphysis using hydroxyapatite with or without simvastatin: effects on healthy, diabetic, and osteoporotic rats. Clinical Oral Investigations, 24(4), $1479-1491$. doi:10.1007/s00784-019-03180-9.

[14] Oishi, A., Yamada, S., Sakamota, H., Kamlya, S., Yanagida, K., Kubota, C., Watanabe, Y. \& Shimizu, R. (1996). Evaluation of Bone Maturation in Japanese Black Beef Cattle. Journal of Veterinary Medical Science, 58(6), 529-535. doi:10.1292/jvms.58.529

[15] S. Ahmed, N. (2008). Development of forelimb bones in indigenous sheep fetuses. Iraqi Journal of Veterinary Sciences, 22(2), 87-94. doi:10.33899/ijvs.2008.5719

[16] Arthur, G. H, Noakes, D. E \& Pearson H. (1989). Veterinary reproduction and obstetrics. 6th ed. Bailliere. Tindall, London; p59.

[17] Salaramoli, J., Sadeghi, F., Gilanpour, H., Azarnia, M. \& Aliesfehani, T. (2015). Modified double skeletal staining protocols with Alizarinred and Alcian blue in laboratory animals. Annals of Military and Health Sciences Research, 13(2), 76-81

[18] Rice, D. P. (2008). Developmental Anatomy of Craniofacial Sutures. Frontiers of Oral Biology (1)12, 1-21. doi:10.1159/000115028.

[19] Hill, M. A. (2020). Embryology Head Development. Available online: https://embryology.med.unsw.edu.au /embryology/index.php/Head_Development (accessed on August 2020).

[20] Dunlop, L. L., \& Hall, B. K. (2002). Relationships between cellular condensation, preosteoblast formation and epithelialmesenchymal interactions in initiation of osteogenesis. International Journal of Developmental Biology, 39(2), 357-371.

[21] Amano, O., Doi, T., Yamada, T., Sasaki, A., Sakiyama, K., Kanegae, H., \& Kindaichi, K. (2010). Meckel's Cartilage: Discovery, Embryology and Evolution:-Overview of the Specificity of Meckel's Cartilage-. Journal of Oral Biosciences, 52(2), 125-135. doi:10.1016/S1349-0079(10)80041-6.

[22] Frommer, J., \& Margolies, M. R. (1971). Contribution of Meckel's cartilage to ossification of the mandible in mice. Journal of Dental Research, 50(5), 1260-1267. doi:10.1177/00220345710500052801.

[23] Ichim, I., Swain, M., \& Kieser, J. A. (2006). Mandibular Biomechanics and Development of the Human Chin. Journal of Dental Research, 85(7), 638-642. doi:10.1177/154405910608500711. 